\title{
Seven-year disease-free survival after radical pneumonectomy for a pulmonary artery sarcoma
}

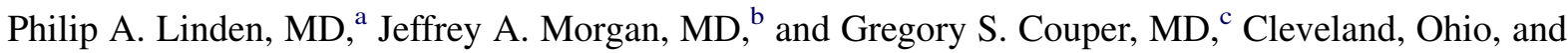 \\ Boston, Mass
}

\begin{abstract}
A 50-year-old woman without significant medical history presented with fatigue, fever, and shortness of breath. She underwent a pulmonary embolus protocol chest computed tomography in January of 2004 that showed filling defects of the proximal right pulmonary artery and an 11-cm right hilar mass. An endobronchial ultrasound-guided biopsy revealed a diagnosis of mixed spindle cell and epithelioid cell neoplasm. She was treated with a standard ifosfamide doxorubicin neoadjuvant regimen, receiving ifosfamide $2500 \mathrm{mg} / \mathrm{m}^{2}$ on days 1 to 3 for each of 6 cycles, together with $25 \mathrm{mg} / \mathrm{m}^{2}$ doxorubicin on days 1 to 3 for each of 4 cycles, and then $20 \mathrm{mg} / \mathrm{m}^{2}$ doxorubicin on days 1 to 3 for cycles 5 and 6, with a marked response. She underwent exploratory thoracotomy at an outside hospital where invasion of the atrium was noted, and the patient was closed without resection.
\end{abstract}

On arrival at our institution in September 2004 she had a chest computed tomography (Figure 1) and a positron emission tomography scan that only showed activity in the right hilum. Pulmonary function tests showed a forced expiratory volume in the first second of expiration of 2.24 (89\% predicted). A cardiac magnetic resonance image showed thickening of the left atrial wall, but did not suggest involvement of the interatrial septum. In October 2004 she underwent a sternotomy. The right pulmonary artery was divided with a stapler just lateral to the superior vena cava (SVC). On bypass, the heart was arrested, the left atrium was opened, and a cuff of left atrium was resected en bloc with primary closure of the left atrium. The bronchus was stapled and divided at its takeoff from the carina. Intraoperative frozen section returned positive on the pulmonary artery, and negative on the bronchus and atrium. The right pulmonary artery was dissected behind the SVC and aorta to its origin off the main pulmonary artery. A portion of

\footnotetext{
From the Division of Thoracic and Esophageal Surgery, ${ }^{\text {a }}$ University Hospitals Case Medical Center, Case Western Reserve School of Medicine, Cleveland, Ohio; Center for Sarcoma and Bone Oncology, ${ }^{\mathrm{b}}$ Dana-Farber Cancer Institute, and Division of Cardiac Surgery, ${ }^{\mathrm{c}}$ Brigham and Women's Hospital and Harvard Medical School, Boston, Mass.

Disclosures: Authors have nothing to disclose with regard to commercial support.

Received for publication Jan 17, 2013; revisions received Feb 7, 2013; accepted for publication April 18, 2013; available ahead of print June 13, 2013.

Address for reprints: Philip A. Linden, MD, University Hospitals Case Medical Center, 11100 Euclid Ave, Cleveland, OH 44106 (E-mail: philip.linden@uhhospitals. org).

J Thorac Cardiovasc Surg 2013;146:e17-8

$0022-5223 / \$ 36.00$

Copyright (c) 2013 by The American Association for Thoracic Surgery

http://dx.doi.org/10.1016/j.jtcvs.2013.04.022
}

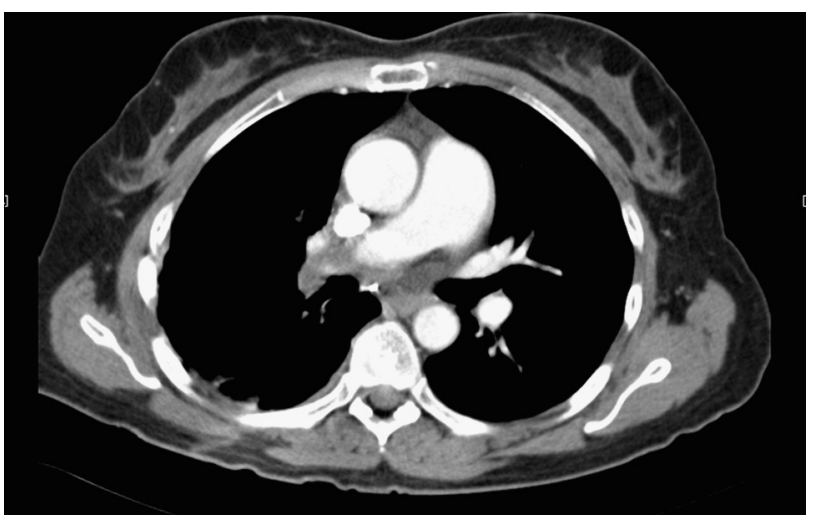

FIGURE 1. Postneoadjuvant chemotherapy computed tomography scan showing a persistent right hilar mass approximately $3 \mathrm{~cm}$ in diameter, which had shrunk from a preoperative measurement of $11 \mathrm{~cm}$ in diameter.

attached SVC and right atrium were resected and reconstructed with bovine pericardium. Sessile lesions were noted in the lumen of the right pulmonary artery that had been reresected. Frozen section at the junction of the right and main pulmonary artery returned positive. The main pulmonary artery was opened and smooth sessile lesions were noted along the wall of the artery that extended to the base of the pulmonic valve leaflets. These returned positive for neoplasia. The origin of the left pulmonary artery appeared free of disease, and the right ventricular outflow tract, as visualized through the pulmonic valve, appeared free of disease. The pulmonic valve, annulus, and adjacent right ventricular muscle were excised and replaced with an aortic valve homograft that was anastomosed to the left main pulmonary artery.

The final pathology was read as malignant pleomorphic spindle cell neoplasm consistent with leiomyosarcoma, with extensive fibrosis and necrosis. The tumor stained positive for smooth muscle actin and CD34, and negative for CK7, CK20, desmin, and s100. Final margins were negative except for the proximal left pulmonary artery where it joined the main pulmonary artery. Post-treatment pathologic staging was T4N1 (2 of 7 hilar nodes were positive).

Postoperative radiation (50 Gy in 25 fractions) was administered 6 weeks after the surgery. The patient is currently off oxygen and is fully functional with an Eastern Cooperative Oncology Group score of 0 . She has been followed up with annual imaging with either chest magnetic resonance imaging and/or positron emission tomography/ computed tomography and remains alive without evidence of recurrent disease 7 years and 8 months after resection. 


\section{COMMENTS}

The largest review of mediastinal sarcomas consists of 47 patients treated between 1940 and 1991. No mention was made as to how many were pulmonary artery sarcomas. Twelve were malignant peripheral nerve tumors, and only 5 were leiomyosarcomas. Malignant peripheral nerve tumor patients had a $36 \%$ five-year survival rate, whereas none of the other sarcoma patients survived for more than 2 years. ${ }^{1}$

Primary pulmonary artery sarcomas are rare, with fewer than 250 patients described in the literature. ${ }^{2}$ In 1995, the largest series until that time, involving 6 cases, was published from the University of California at San Diego. No patient survived longer than 19 months, even with adjuvant chemotherapy and radiation. The invited commentary for this report suggested that "pulmonary artery sarcomas are almost invariably incurable." 3

More recently, a series and review of the literature from MD Anderson Cancer Center showed encouraging results in 8 pulmonary artery sarcoma patients with bimodality and trimodality therapy and aggressive surgical resection. ${ }^{2}$ All were resected via sternotomy on bypass and all received preoperative or postoperative chemotherapy. Five had replacement of the main pulmonary artery, 3 had pulmonic valve replacement, and 5 underwent pneumonectomy. They reported an estimated median survival of 71 months and an estimated 5-year survival of $72.9 \%$, although no patient was alive and disease free beyond 30 months.

Ninety-two months represents one of the longest disease-free survival intervals in a patient with a pulmonary artery sarcoma, and supports aggressive surgical resection along with multimodality treatment in fit patients. The vast majority of long-term survivors in the literature have been treated with either preoperative or postoperative chemotherapy, and underwent radical resection via median sternotomy on cardiopulmonary bypass, with resection of the main pulmonary artery and/or valve with homograft replacement.

An approach via median sternotomy, with cardiopulmonary bypass available, is necessary to avoid futile thoracotomy in these patients. Although resection of the right or left pulmonary artery can be performed without cardiopulmonary bypass, resection of the main pulmonary artery and even resection and replacement of the pulmonary valve, on cardiopulmonary bypass, should be performed if it is believed that negative margins can be achieved. In this patient, microscopic margins were positive on the left pulmonary artery, but long-term, disease-free survival still was achieved with postoperative radiation.

\section{References}

1. Burt M, Ihde JK, Hajdu SI, Smith JW, Bains MS, Downey R, et al. Primary sarcomas of the mediastinum: results of therapy. J Thorac Cardiovasc Surg. 1998; 115:671-80.

2. Blackmon SH, Rice DC, Correa AM, Mehran R, Putnam JB, Smythe R, et al. Management of primary pulmonary artery sarcomas. Ann Thorac Surg. 2009;87: 977-84.

3. Anderson MB, Kriett JM, Kapelanski DP, Tarzi R, Jamieson SW. Primary pulmonary artery sarcoma: a report of six cases. Ann Thorac Surg. 1995;59: 1487-90.

\title{
Cerebral air embolism during an aircraft flight in a passenger with an air-filled lung cavity associated with remote lung surgery
}

\author{
François-Pierrick Desgranges, MD, ${ }^{\mathrm{a}}$ Martin Cour, MD, ${ }^{\mathrm{a}, \mathrm{b}}$ Romain Hernu, MD, ${ }^{\mathrm{a}}$ \\ Bertrand Delafosse, $\mathrm{MD},{ }^{\mathrm{c}}$ and Laurent Argaud, MD, PhD, ${ }^{\mathrm{a}, \mathrm{b}}$ Lyon, France
}

\footnotetext{
From the Service de Réanimation Médicale, ${ }^{a}$ Hospices Civils de Lyon, Groupement Hospitalier Edouard Herriot, Lyon, France; Faculté de Médecine Lyon-Est, ${ }^{b}$ Université Claude Bernard Lyon I, Lyon, France; and Centre d'Oxygénothérapie Hyperbare, ${ }^{\mathrm{c}}$ Hospices Civils de Lyon, Groupement Hospitalier Edouard Herriot, Lyon, France.

Disclosures: Authors have nothing to disclose with regard to commercial support.

Received for publication March 8, 2013; revisions received April 24, 2013; accepted for publication May 2, 2013; available ahead of print June 24, 2013.

Address for reprints: Laurent Argaud, MD, PhD, Réanimation Médicale, Groupement Hospitalier Edouard Herriot, 5, Place d'Arsonval, 69437 Lyon cedex 03, France (E-mail: laurent.argaud@chu-lyon.fr).

J Thorac Cardiovasc Surg 2013;146:e18-20

$0022-5223 / \$ 36.00$

Copyright (c) 2013 by The American Association for Thoracic Surgery

http://dx.doi.org/10.1016/j.jtcvs.2013.05.008
}

Cerebral air embolism (CAE) is a rare cause of stroke and a potentially life-threatening event. ${ }^{1}$ The incidence of inflight emergencies on commercial airline flights is low. ${ }^{2}$ A few cases of CAE during air travel, associated with the disruption of a bronchogenic cyst, have been reported in the literature. ${ }^{3}$ To our knowledge, we describe the first case of severe CAE during an aircraft flight, secondary to an air pulmonary bulla that developed after lung surgery.

\section{CLINICAL SUMMARY}

A 67-year-old man experienced a sudden loss of consciousness 60 minutes after takeoff of a 2-hour commercial flight. He had a history of lung cancer in the right superior 